\title{
Successful haemofiltration therapy in severe phenobarbital overdose
}

\section{Elizabeth Tan ${ }^{1}$, Maximilian Moser ${ }^{2}$, and Graeme Duke ${ }^{3}$}

\section{1,2,3. Box Hill Hospital, Australia}

\section{CASE STUDY}

Please cite this paper as: Tan E, Moser M, Duke G. Successful haemofiltration therapy in severe phenobarbital overdose. AMJ 2018;11(2):91-95.

https://doi.org/10.21767/AMJ.2018.3307

Corresponding Author:

Elizabeth Tan

8 Arnold St, Box Hill Hospital, Box Hill

Victoria 3128, Australia

Email: etan6193@gmail.com

\section{ABSTRACT}

In the $19^{\text {th }}$ century, barbiturates were first-line treatment as hypnotic and anticonvulsants, then gradually replaced by agents with a safer clinical profile. However, its ongoing use in Australian veterinary medicine and steadfast prescriptions in developing countries/our migrant population, still contributes to overdoses.

We present a case of a middle-aged man with a lifethreatening phenobarbital overdose. Haemofiltration was trialled, causing a rapid fall in phenobarbital levels and a speedy recovery. Through a review of the literature, treatment options of barbiturate overdose presentations will be discussed. It is imperative clinicians are aware of barbiturate's mechanism and its enhanced elimination through extracorporeal treatment.

\section{Key Words}

Phenobarbital overdose, haemofiltration, extracorporeal treatment

\section{Implications for Practice:}

\section{What is known about this subject?}

Barbiturates were once a very common cause of drug dependence and overdoses. Extracorporeal elimination has been trialled in low-quality evidence only, with positive conclusions.

\section{What new information is offered in this case study?}

Phenobarbital overdose of this prolonged period has rarely been reported in the literature. The trial of haemofiltration successfully eliminated the drug, facilitating early recovery.

3. What are the implications for research, policy, or practice?

In the absence of adequate phenobarbital elimination with forced alkaline diuresis, clinicians should consider extracorporeal treatment; so as to prevent prolonged hospital stay and complications.

\section{Background}

Barbiturates were commonly prescribed as an anti-epileptic and sedative in the 1930s and 1940s, peaking to 24.7 million American barbiturate prescriptions in $1968 .{ }^{1}$ Its major drawbacks of dependence and overdose-related deaths subsequently led to heavy restriction laws. ${ }^{2}$ Prescription rates have also declined with the development of safer antiepileptics like levetiracetam and anxiolytics like benzodiazepine. $^{3}$ Despite these two factors, acute barbiturate poisoning is still common due to its affordability in developing countries and ongoing prescription in human/animal epilepsy disorders such as partial and tonicclonic generalized seizures. ${ }^{4}$

Clinicians need to recognise the symptoms and physiology of barbiturate overdose. In a minor toxicity scenario, supportive care and forced alkaline diuresis may be sufficient therapeutic options. However, in severe overdoses, early recognition of when conservative management is no longer justified and consideration of extracorporeal treatment is critical; this will enhance drug elimination. Speedier neurological and clinical recovery will decrease hospital stay and complication risks such as ventilator-associated pneumonia and pressure ulcers. ${ }^{3,4}$

\section{Case details}

A 45-year-old man with no past medical history was found unconscious at home and brought to the Emergency 
department. At the scene, paramedics noted empty packaging for $200 \times 30 \mathrm{mg}$ phenobarbital tablets $(60 \mathrm{~g})$, $50 \times 600 \mathrm{mg}$ potassium chloride extended release (slow-K) tablets $(30 \mathrm{~g})$, and a $40 \mathrm{mg}$ clonazepam liquid bottle. He last had contact with a relative 19 hours prior. He had recently moved to Australia and had no known stressors or previous substance abuse. A polypharmacy induced coma was suspected.

The patient's respiratory rate (RR) was 10 breaths per minute, with 96 per cent oxygen saturation on $10 \mathrm{~L}$ Hudson mask, tachycardic at 140 beats per minute (bpm), noninvasive blood pressure (NIBP) $100 / 60 \mathrm{mmHg}$ and febrile at 38.8 degrees Celsius. ECG showed no arrhythmias or electrophysiological signs of hyperkalaemia. With a Glasgow Coma Scale (GCS) score of $3 / 15$ and bilaterally $2 \mathrm{~mm}$ reactive pupils, he was intubated. Systemic examination was otherwise unremarkable.

Other than a creatinine kinase(CK) of 1820IU/L (normal range 60-220IU/L), blood results and toxicology screen were unremarkable. Importantly, potassium was normal at $4.2 \mathrm{mmol} / \mathrm{L}$, confirming that he had not ingested the slow-K. His abdominal X-Ray showed no undissolved tablets hence whole bowel irrigation was deemed unnecessary. Chest XRay and CT brain were-performed and did not reveal another cause. Post fluid resuscitation, he was transferred to intensive care for ventilation and vasopressor support with noradrenaline. No sedation was given. Forced alkaline diuresis with sodium bicarbonate was commenced.

The first phenobarbital level approximately 19 hours from time of ingestion was $172.9 \mathrm{mg} / \mathrm{L}$ (normal range 15.1$39.4 \mathrm{mg} / \mathrm{L}$ ). After approximately four days of forced alkaline diuresis, he still had no clinical neurological response (GCS3/15- Eyes $1 / 4$, Verbal $1 / 5$, Motor $1 / 6$ ) and the second phenobarbital level was $162.4 \mathrm{mg} / \mathrm{L}$ (see Figure 1).

Given his weight of $67 \mathrm{~kg}$, his estimated Total Water Content (TWC) was $40.2 \mathrm{~L}$ (60 per cent of $67 \mathrm{~kg}$ ). The volume of drug distribution was estimated at $347.02 \mathrm{~L}$ $\left(V_{d}=D / C_{0}=60 \mathrm{~g} / 0.1729 \mathrm{~g} / \mathrm{L}\right)$. Hence, a 10-hour trial of intermittent haemofiltration was commenced via right femoral vascular catheter. An AV600S filter was used; settings included a blood flow rate of $250 \mathrm{ml} /$ minute with pre-dilution $100 \mathrm{ml} /$ minute, with part $\mathrm{A} \mathrm{HD} / \mathrm{F} 2$, potassium at $4 \mathrm{mmol} / \mathrm{L}$, sodium $140 \mathrm{mmol} / \mathrm{L}$, and bicarbonate $32 \mathrm{mmol} / \mathrm{L}$ at 36.5 degrees Celsius. A heparin infusion was used concurrently at 300 units per hour, with target APTT range 50-80 seconds.
Approximately four hours after commencement of haemofiltration, spontaneous eye movements and semipurposeful movements returned. Propofol sedation at $50 \mathrm{mg} /$ hour was commenced for airway safety. After 10 hours haemofiltration, his phenobarbital level dropped to $119.7 \mathrm{mg} / \mathrm{L}$. nine hours later, his GCS was 13/15 (E3, V4, M6), in association with a drug level of $49 \mathrm{mg} / \mathrm{L}$ (See Figure 1). The patient was extubated 5 days post-intubation and 1 day post haemofiltration commencement, with full neurological recovery (See Table 1). Given his full recovery with a phenobarbital level of $49 \mathrm{mg} / \mathrm{L}$, we did not repeat the test till it was $0 \mathrm{mg} / \mathrm{L}$. This is because it was neither cost effective nor clinically needed. It is likely to decrease with ongoing liver metabolism over time. His rhabdomylysis resolved and post psychiatric review, he was discharged into his family's care.

\section{Discussion}

Phenobarbital is a long-acting barbiturate that binds to gamma-amino butyric acid (GABA) receptors increasing GABAergic transmissions. This inhibits central nervous system excitability. ${ }^{5}$ With a potential toxicity level at $>40 \mathrm{mcg} / \mathrm{mL}^{5}$ post ingestion of $60 \mathrm{~g}$ of the drug, our patient's initial serum level was $172.9 \mathrm{mg} / \mathrm{L}$. Toxicity presents as sedation that can ultimately progress to coma, respiratory depression, hypotension, and cardiac arrest or death. ${ }^{6}$ With a prolonged half-life of 53-118 hours, secondary to its liver metabolism and renal excretion, serum drug levels take days to decline. ${ }^{6}$ For our patient, this resulted in 4 days of prolonged intubation. It was likely further compounded by the additional 40mg clonazepam that was ingested, a central nervous system depressant. ${ }^{5}$

The fundamentals of poisoning management include supportive care, prevention of further poison absorption, enhanced elimination and antidote administration. ${ }^{5}$ Our patient received supportive care in the form of invasive airway and ventilatory support and haemodynamic support (intravenous fluid therapy and noradrenaline). Multiple dose activated charcoal was deemed a low-yield intervention given the clinical lack of bowel motility increasing the risk of bowel obstruction. Charcoal therapy was also deemed inappropriate because plasma concentrations generally peak $1-4$ hours post-ingestion and the patient had presented 19 hours after ingestion. ${ }^{5}$

Phenobarbital plasma concentrations were analysed with the Emit ${ }^{\circledR} 2000$ Assay, a test with high sensitivity. It is based on competition for antibody binding sites between the sample's drug and drug labelled with the glucose-6phosphate dehydrogenase (G6PDH) enzyme. As our 
patient's drug level was above the assay range $(80 \mathrm{mg} / \mathrm{L})$, sample dilution was required. ${ }^{7}$

We considered using flumazenil, a non-specific competitive antagonist of the benzodiazepine (BZD) receptor, ${ }^{8}$ to reverse his overdose. However, its use remains highly controversial, due to the risk of precipitating seizures. ${ }^{8}$

Due to two reasons, we speculated that the $40 \mathrm{mg}$ clonazepam was unlikely to be contributing to his coma at four days post-ingestion. Firstly, clonazepam, a long-acting BZD, has a half-life of 18-50 hours (up to date ref). Like any other drug, after four half-lives, only 6.25 per cent of the drug is left; resulting in a negligible therapeutic effect. ${ }^{8}$ Given our patient was relatively young with no liver impairment, it would have taken approximately 72 hours $(18 \times 4)$ to reach less than 6.25 per cent. Secondly, phenobarbital is an inducer of CYP3A4, a liver enzyme that metabolizes benzodiazepines to a significant extent. ${ }^{8}$ This enhanced metabolism would have further reduced his clonazepam level. Hence, there would have been minimal or no clonazepam to contribute to his coma status at day 4 (96 hours) post-ingestion.

Based on the recent Extracorporeal Treatments in Poisoning (EXTRIP) workgroup guidelines, our patient was suitable for extracorporeal treatment. ${ }^{9}$ He was in a prolonged coma necessitating mechanical ventilation, with persistently elevated serum barbiturate concentrations. There have been multiple case reports regarding successful extracorporeal treatment in severe barbiturate intoxication. ${ }^{3,4,6,9-14}$

Haemodialysis involves solute removal by diffusion whereas haemofiltration uses convection with hydrostatic pressure inducing plasma water filtration across the haemofilter. ${ }^{6}$ Haemoperfusion is ideal in the removal of lipid soluble or highly protein bound drugs. ${ }^{6}$ Haemodialysis and haemofiltration is highly effective for phenobarbital due to its high-water solubility, low molecular weight and small volume of distribution. ${ }^{6}$ Its plasma clearance by high-flux haemodialysis is 30 times that of hepatic clearance, and 10 times that of activated charcoal clearance. ${ }^{2,15}$ Although the estimated $V_{d}$ was high at $347.02 \mathrm{~L}$, suggesting that there was a higher concentration in tissues than in plasma, the other factors mentioned above convinced us that extracorporeal treatment was still feasible. Due to the high cost and lack of availability with haemoperfusion, and our haemodialysis machines having low-efficiency with low blood flow rates, we opted for haemofiltration.
Given that haemofiltration removes low molecular weight substances, we also compared the removal of other small molecules such as Blood Urea Nitrogen (BUN) and creatinine. As illustrated in Table 2, they were measured pre-haemofiltration, during, and after-dropping in a similar fashion to his phenobarbital level (Figure 1).

Robert and Buckley's systematic review16 of 94 publications found no role for urine alkalinisation. This was echoed in our case where 4 days of urine alkalinisation only decreased the patient's barbiturate levels by 6 per cent. The trial of haemofiltration in our case significantly decreased phenobarbital level by 26 per cent immediately post haemofiltration and a total decrease of 69.8 per cent. This stark contrast in elimination rates of the drugs from 69.8 per cent with haemofiltration and 6 per cent with urinary alkalinsation confirms the superiority of extracorporeal modalities in reducing coma duration. ${ }^{16}$

The clinical benefit of haemofiltration is evident in our patient's rapidly improved neurological function and progressive drop in phenobarbital blood concentration in association with 10 hours of haemofiltration (Figure 1 and Table 1). Complications such as mechanical ventilationassociated pneumonia, cardiorespiratory compromise and pressure ulcers were also avoided/ minimised. In addition to the clinical benefits, reduction in length of ICU stay would also reduce overall healthcare costs. The value of extracorporeal haemofiltration can be further extrapolated to the treatment of other drug poisonings, although further research is necessary.

\section{Conclusion}

Thus, our case illustrates a significant decrease in phenobarbital blood levels with haemofiltration, where initial supportive care was unsuccessful. This enhanced elimination rate far exceeded endogenous elimination rates, facilitating early recovery with no complications and also decreasing ICU and hospital length of stay. Haemofiltration appears a valuable therapeutic option in severe phenobarbital intoxication, with further evaluation needed to help determine Australian guidelines.

\section{References}

1. Plant M. What aetiologies? In: Edwards G, Busch C, editors. Drug problems in Britain. A review of ten years. London: Academic Pr; 1981; pp. 245-80.

2. Johns MW. Self-poisoning with barbiturates in England and Wales during 1959-74. $\mathrm{Br}$ Med J. 1977;1(6069):1128-30. 
3. Hoyland K, Hoy M, Austin R, et al. Successful use of haemodialysis to treat phenobarbital overdose. BMJ Case Rep. 2013. Doi:10.1136/bcr-2013-010011.

4. Thuan LQ, Ngoc ND, Due P. Effectiveness of Continuous Veno-Venous hemofiltration and Intermittent Haemodialysis in the Treatment of Severe Acute Phenobarbital Poisoning. Asia Pacific J Medical Toxicology. 2013;2;1:10-13

5. Linden $\mathrm{CH}$, Burns MJ. Poisoning and drug overdose. In: $\mathrm{E}$ Braunwald, AS Fauci, DL Kasper, SL Hauser, DL Longo, JL Jameson, editors. Harrison's Principles of Internal Medicine. $15^{\text {th }}$ ed. USA: The McGraw-Hill Co. Inc; 2001;2595-2605.

6. Jana S, Chakravarty C, Taraphder A, et al. Successful use of sustained low efficiency dialysis in a case of severe phenobarbital poisoning. Indian J Crit Care Med. 2014;18(8):530-532.

7. Beckman Coulter. Emit ${ }^{\circledR} 2000$ Phenobarbital Assay. Aug 2010.

https://www.beckmancoulter.com/wsrportal/techdocs? docname=/cis/4D052/\%25\%25D/EN_PHENO

8. Greller H, Gupta A. Benzodiazepine poisoning and withdrawal. In Traub S.J, Grayzel (Eds.), 2017. UptoDate. Available from https://www.uptodate.com/contents/benzodiazepinepoisoning-andwithdrawal?search=Benzodiazepine\%20poisoning\%20an d\%20withdrawal\&source=search_result\&selectedTitle=1 150\&usage_type=default\&display_rank=1

9. Mactier R, Laliberte M, Mardini J, et al. Extracorporeal Treatment for Barbiturate Poisoning: Recommendations from the EXTRIP Workgroup. Am J Kidney Dis. 2014;64(3):347-358.

10. Jacobs F, Brivet FG. Conventional haemodialysis significantly lowers toxic levels of phenobarbital. Nephrol Dial Transplant. 2004;19:1663-4.

11. Mohammed E, Abdel-rahman HM. Pharmacokinetics of phenobarbital during certain enhanced elimination modalities to evaluate their clinical efficacy in management of drug overdose. Ther Drug Monit. 2001;23(3):209-216.

12. Lee DC, Ferguson KL. Sedative-Hypnotics. In: Nelson LS, Lewin NA, Howland MA, Hoffman RS, Goldfrank LR, Flomenbaum NE, editors. Goldfrank's Toxicologic Emergencies. $9^{\text {th }}$ ed. New York: McGraw-Hill; 2011. $\mathrm{P}, 1060-71$.

13. van de Plas A, Stolk L, Verhoeven MA, et al. Successful Treatment of Acute Phenobarbital Intoxication by Hemodiafiltration. Clinical Toxicology. 2006;44(1):93-94

14. Palmer BF. Effectiveness of haemodialysis in the extracorporeal therapy of phenobarbital overdose. Am J Kidney Dis. 2000; 36:640-643.
15. Quan DJ, Winter ME. Extracorporeal removal of phenobarbital by high-flux haemodialysis. J Appl Ther Res. 1997;2:75-9.

16. Roberts DM, Buckley NA. Enhanced elimination in acute barbiturate poisoning- a systematic review. Clin Toxicol (Phila). 2011;49(1):2-12. doi: 10.3109/15563650.2010.550582.

\section{PEER REVIEW}

Not commissioned. Externally peer reviewed.

\section{CONFLICTS OF INTEREST}

The authors declare that they have no competing interests.

\section{FUNDING}

None

\section{PATIENT CONSENT}

The authors, Tan E, Moser M, Duke G, declare that:

1. They have obtained written, informed consent for the publication of the details relating to the patient(s) in this report.

2. All possible steps have been taken to safeguard the identity of the patient(s).

3. This submission is compliant with the requirements of local research ethics committees. 
Figure 1: Graph demonstrating phenobarbital elimination over time

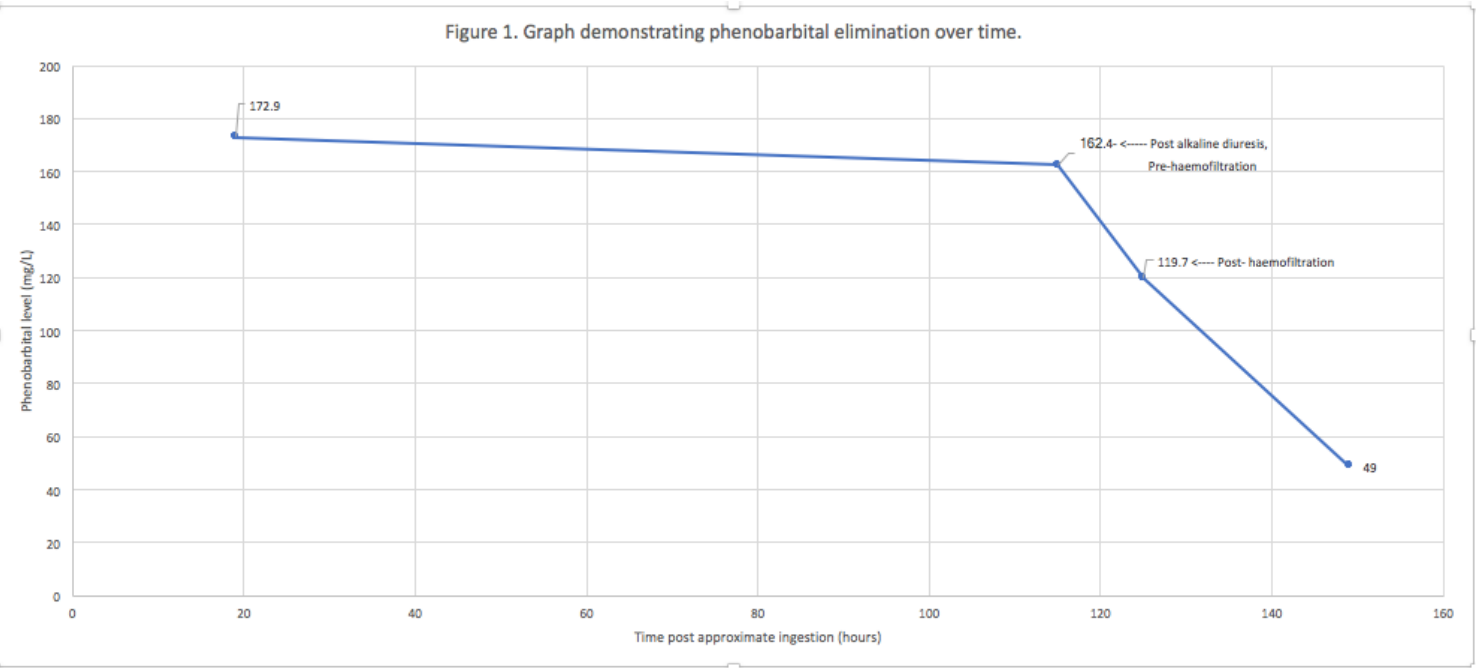

Table 1: Timeline of the interventions and corresponding patient neurological progress

\begin{tabular}{|c|c|c|c|c|c|c|}
\hline & Day 0 & Day 1 & Day 2 & Day3 & Day 4 & Day 5 \\
\hline GCS & $3 / 15$ & $3 / 15$ & $3 / 15$ & $3 / 15$ & $\begin{array}{l}3 / 15 \\
5 / 15 \text { ( } 4 \text { hours } \\
\text { into HF) } \\
13 / 15 \text { ( } 19 \text { hours } \\
\text { post HF) }\end{array}$ & $15 / 15$ \\
\hline \multirow{3}{*}{ Intervention } & Intubation & & & & & Extubation \\
\hline & \multicolumn{6}{|c|}{ Forced alkaline diuresis } \\
\hline & & & & & $\begin{array}{l}\text { Hemofiltration } \\
\text { (HF) }\end{array}$ & \\
\hline $\begin{array}{l}\text { Phenobarbital } \\
\text { level (mg/L) }\end{array}$ & 172.9 & & & 162.4 & $\begin{array}{l}119.7 \text { ( } 10 \text { hours } \\
\text { post HF) } \\
49 \text { (19 hours post } \\
\text { HF) }\end{array}$ & \\
\hline
\end{tabular}

Table 2: Comparison of Creatinine, Urea, and Blood urea nitrogen levels with the intervention of haemofiltration

\begin{tabular}{|l|r|r|r|r|r|}
\hline $\begin{array}{l}\text { Time in relation to } \\
\text { haemofiltration (HF) }\end{array}$ & Pre- HF & $\begin{array}{l}\text { 4 hours } \\
\text { into HF }\end{array}$ & $\begin{array}{l}\text { 3 hours } \\
\text { post HF }\end{array}$ & $\begin{array}{l}\text { 1 day } \\
\text { post HF }\end{array}$ & $\begin{array}{l}\text { 2 days } \\
\text { post HF }\end{array}$ \\
\hline $\operatorname{Cr}(60-110 \mathrm{mmol} / \mathrm{L})$ & 69 & 42 & 47 & 54 & 76 \\
\hline Ur2.8-8.1mmol/L & 4.6 & 2.4 & 2.8 & 4.3 & 5.7 \\
\hline BUN (2.5-7.1mmol/L) & 2.15 & 1.12 & 1.31 & 2.24 & 2.66 \\
\hline
\end{tabular}

